* Doutora em Ciências Sociais pela Universidade Federal da Bahia (UFBA). Docente do Bacharelado em Cinema e Audiovisual e do Programa de PósGraduação em Memória: Linguagem e Sociedade, da Universidade Estadual do Sudoeste da Bahia (UESB). Analista Sudoeste da Bahia (UESB). Analista
universitária da mesma instituição, universitária da mesma instituição,
atuando como coordenadora-geral do atuando como coordenadora-geral do Uesb. Líder do grupo de pesquisa Cinema e Audiovisual: Memória e Processos de Formação Cultural, vinculado à UESB, e pesquisadora do grupo Cultura, Memória e Desenvolvimento, vinculado à Universidade de Brasília. E-mail: mcsgusmao@gmail.com.

**Doutoranda pelo Programa de PósGraduação em Memória: Linguagem e Sociedade, da Universidade Estadual do Sudoeste da Bahia (UESB). Analista universitária da UESB, atuando na coordenação do Programa Janela Indiscreta Cine-Vídeo Uesb. Pesquisadora dos grupos Cinema e Audiovisual: Memória e Processos de Formação Cultural, vinculado à UESB, e Cultura, Memória e Desenvolvimento, vinculado à Universidade de Brasília. E-

mail: quelcosta9@hotmail.com.

\section{Cinema, memória e processos de formação cultural: algumas considerações sobre percursos de pesquisa}

Milene de Cássia Silveira Gusmão*

Raquel Costa Santos**

Resumo:

O texto traz reflexões ancoradas na trajetória do grupo de pesquisa Cinema e Audiovisual: Memória e Processos de Formação Cultural. Trata-se de explicitar caminhos trilhados nos trabalhos desenvolvidos pelos pesquisadores que compõem o grupo, apresentando os objetos construídos a partir da relação temática entre cinema, memória e processos de formação cultural, bem como as interlocuções acadêmicas estruturadas a partir dos percursos teórico-metodológicos mobilizados nas pesquisas.

\section{Abstract:}

The text brings reflections anchored on the trajectory of the research group "Cinema and Audiovisual: Memory and Cultural Formation Processes". It is explicit paths taken in the work developed by researchers who make up the group, presenting the objects constructed from the thematic relationship between cinema, memory and cultural formation processes, as well as academic dialogues structured from the theoretical and methodological paths mobilized in the searchs.

Dossiê Cinema e Audiovisual: entre o sensível e o reflexivo

Arquivos do CMD, Volume 3, N. 1. Jan/Jul 2015 
Desconhecemos completamente as condições sob as quais uma espécie de seres vivos emergiu de um processo evolutivo apetrechada não só para aprender com seus antepassados, mas também para armazenar e potencialmente poder se beneficiar com as experiências ancestrais realizadas e transmitidas, ao longo do tempo, através de uma seqüência contínua de gerações (ELIAS, 2002, p. 16).

A trajetória apresentada a seguir diz respeito aos percursos investigativos ancorados pelo grupo de pesquisa Cinema e Audiovisual: Memória e Processos de Formação Cultural. Reunindo pesquisadores de diversas áreas do conhecimento, o grupo visa a contribuir tanto para o debate sócio-histórico sobre a articulação temática entre produção simbólica nos âmbitos do cinema e do audiovisual e processos de significação na sociedade contemporânea quanto para reflexões acerca do papel da memória (social e individual) nos processos de aprendizagem entre gerações. Nessa última visada, são desenvolvidos trabalhos que tratam de perspectivas metodológicas inclusivas de teorias oriundas de diferentes campos disciplinares para subsidiar aproximações entre memória, educação, processos de formação cultural e produção audiovisual. A tônica analítica da temática posta pelo grupo destaca, ainda, como os modos e estilos de vida na contemporaneidade correspondem a expressividades mediadas pelos fluxos de informação que conformam mercados e circuitos de produção e consumo simbólico.

O grupo se constituiu em 2009, a partir da convergência de alguns fatores complementares relacionados a trajetórias individuais e coletivas que, entrecruzados em pontos de interesses práticos e teóricos comuns, resultaram na sua proposição e na institucionalização pela Universidade Estadual do Sudoeste da Bahia (UESB), com participação de membros de diversas outras universidades do país. O primeiro desses fatores diz respeito ao acúmulo das vivências da líder do grupo, Milene de Cássia Silveira Gusmão, no dia a dia de trabalho como membro da equipe coordenadora do Programa Janela Indiscreta Cine-Vídeo Uesb, Desde o final dos anos 1990. Essa experiência viabilizou oportunidades de ampliação do conhecimento acerca das questões do cinema e do audiovisual no país, apontando o caminho da primeira pesquisa em cinema realizada antes da estruturação do grupo, 
que toma memórias do cinema em Vitória da Conquista, Bahia, como objeto de estudo.

A referida pesquisa foi realizada para a dissertação de mestrado em Memória Social e Documento na Universidade Federal do Estado do Rio de Janeiro (UniRio), defendida em 2001. Intitulado Uma janela para o mundo: memória e cinema em Vitória da Conquista, o trabalho buscou, a partir de um recorte teórico referenciado no tema da memória, compreender a importância do cinema no cotidiano das pessoas e o seu valor na consolidação de práticas e representações sociais. Apresentando o percurso do cinema em Vitória da Conquista desde 1912, quando foi inaugurado o primeiro espaço de projeção na cidade, até 2000, quando existia apenas uma sala em funcionamento, buscou-se responder à hipótese de que a cidade, como espaço urbano constituído pelas relações sociais, expressava, como uma das suas características culturais marcantes, a relação peculiar com o cinema. Foram escolhidas três práticas como exemplos de percursos que relacionam o cinema ao cotidiano das pessoas e, consequentemente, à cidade. A primeira prática analisada diz respeito à exibição cinematográfica alternativa ao circuito comercial da cidade e relata o percurso tecido entre a experiência dos cineclubes existentes na cidade, até o início dos anos 1980, e o trabalho desenvolvido pelo Programa Janela Indiscreta Cine-Vídeo, a partir de 1992, na UESB. A segunda refere-se à trajetória desenvolvida por um grupo de cinéfilos conquistenses no sentido de reconstruir a memória de Glauber Rocha, relacionando-a à cidade, lugar do seu nascimento. A terceira prática relacionada ao cinema na cidade, ancorada na atitude do colecionador, diz respeito à Coleção Preciosa, de propriedade do Sr. Willy Flick, técnico em refrigeração, projecionista do Cine Ritz, que colecionou, durante 52 anos, tudo o que pôde encontrar sobre cinema.

Do estudo realizado, restaram algumas inquietações que acabaram por viabilizar o projeto de pesquisa aprovado na seleção para o doutorado. Naquele momento, a questão norteadora referia-se ao consumo cultural do cinema no final do século XX e início do século XXI, observando as mudanças ocorridas a partir das migrações dos espaços públicos para os espaços privados e as transformações do consumo cinematográfico tecidas nos modos de vida e na construção 
de identidades na contemporaneidade. Entretanto, no decorrer do curso de doutorado, durante o cumprimento dos créditos disciplinares, a construção do objeto, antes circunscrita aos campos da memória e da história, ampliou-se para o campo sociológico, orientando-se para a compreensão das regularidades do comportamento humano, ou seja, para a percepção dos tipos de desenhos e das especificidades históricoempíricas das reciprocidades humanas. A partir daí, a pesquisa passou a exigir um enfoque teórico-metodológico que desse conta dos processos sociais na longa duração, constitutivos da configuração do cinema no mundo, e das relações interdependentes desses processos no Brasil e na Bahia, considerando tanto os fluxos entre os diferentes agentes e instituições no desenvolvimento das práticas quanto as condições de transmissividade, entre as gerações, dos saberes e fazeres relacionados ao consumo cinematográfico. Para isso, tornou-se necessário recorrer a estudos e debates no âmbito da teoria sociológica, que se empenharam em compreender os fenômenos da percepção social, observando as relações de poder decorrentes das práticas sociais constituídas a partir da produção e do consumo de bens simbólicos.
Nessa perspectiva, o percurso teórico articulou as contribuições de autores clássicos e contemporâneos, considerando a importância das reflexões tecidas por Georg Simmel e Walter Benjamin sobre as transformações ocasionadas nos modos de vida a partir da modernidade, bem como os desenvolvimentos teóricos contemporâneos propiciados pelas colaborações de Norbert Elias e Pierre Bourdieu, quando acolhem, no campo epistemológico da Sociologia, abordagens que propõem a superação da dicotomia sujeito/objeto, promovida pela modernidade. Nessas propostas de síntese, interessa perceber como, nas relações sociais, mobilizam-se estoques de conhecimento, por meio das mediações simbólicas propiciadas por propriedades como linguagem, memória e potencialidades para o aprendizado individual e coletivo, veiculando padrões de comportamentos e sentimentos entre membros de uma mesma geração e entre agentes de distintas gerações. A tese foi defendida em 2008, no Programa de Pós-Graduação em Ciências Sociais da Universidade Federal da Bahia (UFBA). 
O segundo fator diz respeito à participação no grupo Cultura, Memória e Desenvolvimento (CMD), atualmente alocado junto ao Programa de Pós-Graduação em Sociologia da Universidade de Brasília (UnB), mas criado em 2002, no acima referido Programa de Pós-Graduação em Ciências Sociais da UFBA, sob a liderança do professor Edson Silva de Farias. As pesquisas e reflexões do grupo tomam a triangulação entre cultura, memória e economia, observando suas repercussões tanto na produção e no acesso aos bens simbólicos quanto no plano das políticas públicas. Exploram, em seus objetos de conhecimento, os chamados sistemas de práticas lúdico-artísticas em intercessões com os sistemas técnico-informacionais, com as dinâmicas e circuitos dos distintos mercados (moda, gastronomia, fonografia, audiovisual, entre outros), com as razões do Estado-nação e, sobretudo, com as repercussões de todos esses aspectos nas permanências e nos remanejamentos próprios à esfera cultural contemporânea. Para tanto, o foco teórico-analítico da abordagem é a ressignificação de memórias à luz do debate socioantropológico da transmissão e incorporação de saberes.
A realização de seminários de pesquisa do CMD a partir de 2003 em Vitória da Conquista - além de Salvador e, posteriormente, Brasília -, bem como a participação de membros do grupo como docentes da especialização em Educação, Cultura e Memória do Museu Pedagógico da UESB, possibilitou maior interlocução entre pesquisadores e resultou em trabalhos que deram subsídios à formulação do projeto e à implantação, em 2007, do mestrado acadêmico em Memória: Linguagem e Sociedade, no campus da UESB em Vitória da Conquista, bem como à aprovação do projeto e a implantação do doutorado em 2012.

O terceiro fator se refere aos encontros, mediante as atividades de organização dos seminários, cursos e oficinas da Mostra Cinema Conquista, nas edições de 2004 a 2009, entre cineastas, pesquisadores e educadores preocupados com a temática dos processos de formação pelo cinema e audiovisual. Tais atividades proporcionaram o projeto da Rede Latino-Americana de Educação, Cinema e Audiovisual (Rede Kino), que foi criada em 2009, na Faculdade de Educação da Universidade Federal de Minas Gerais (UFMG), com o intuito de 
congregar pessoas e instituições para compartilhar experiências e somar esforços com vistas a viabilizar ações conjuntas.

Entre esses encontros, que resultaram na formulação da proposta do grupo de pesquisa, está o com a professora Rosália Maria Duarte, do Programa de Pós-Graduação em Educação da Pontifícia Universidade Católica do Rio de Janeiro (PUC-Rio) e vice-líder do grupo. O trabalho de pesquisa realizado por ela para sua tese de doutorado em Educação, defendida na PUC-Rio em 2000, analisa a formação da geração cinematográfica que irrompe no cinema nacional entre a segunda metade dos anos 1960 e a segunda metade dos anos 1970 na cidade do Rio de Janeiro. Tomando como referência a teoria dos campos desenvolvida por Pierre Bourdieu, o estudo procura descrever e analisar as seguintes questões: 1) valores, crenças, códigos, sistemas simbólicos e classificatórios que dão sentido às relações estabelecidas no interior do microcosmo cinematográfico; 2) condições sociais de produção observando o ambiente social e cultural que envolve a socialização de cineastas inscritos num setor geracional específico; e 3) o processo de aprendizagem da técnica cinematográfica propriamente dita.

Assim, os trânsitos nas ambiências acima relacionadas possibilitaram perceber a existência permanente e extensiva de pessoas atuando para difundir práticas e constituir organizações que se ocupam com processos de significação mediante consumo cinematográfico e audiovisual, motivadas a compreender os usos e efeitos que certas alianças humanas mobilizam quando investem na constituição de acervos e na transmissão de conhecimentos e valores, evidenciando metodologias e práticas pedagógicas.

\section{Interlocuções acadêmicas e percursos de pesquisa}

Várias reflexões apontadas nas pesquisas supracitadas, bem como as discussões possibilitadas nos seminários anuais do grupo CMD e na especialização em Educação, Cultura e Memória, tornaramse objeto de estudo para discentes que se interessaram por ampliá-las e aprofundá-las em seus projetos de mestrado e doutorado. A maioria 
deles ancorou-se, então, no Grupo de Pesquisa Cinema e Audiovisual: Memória e Processos de Formação Cultural e no projeto de pesquisa Memória, Cinema e Processos de Formação Cultural, da linha de pesquisa em Memória, Cultura e Educação do Programa de PósGraduação em Memória: Linguagem e Sociedade da UESB (PPGMLS).

O primeiro desses desdobramentos foi o trabalho de Raquel Costa Santos, que realizou pesquisa para dissertação de mestrado defendida no Programa de Pós-Graduação em Ciências Sociais da Pontifícia Universidade Católica de São Paulo (PUC-SP), em 2009, intitulada: Lição de Coisas: Igreja Católica e formação cultural para o cinema no Brasil e na Bahia. O trabalho analisa a influência da Igreja Católica na formação cultural para o cinema no Brasil e na Bahia até a década de 1960. A despeito do relevo que diversos estudos deram à atuação da Igreja como aparelho censor do cinema, a análise desenvolve-se a partir do papel da instituição religiosa na configuração de práticas sociais de cinema, baseadas num projeto histórico de utilização da imagem. O percurso teórico-metodológico é ancorado na memória, considerando-a como categoria, objeto do conhecimento e fato no mundo. Essa relação entre memória e cinema possibilita compreender como se dá a concatenação de habitus, práticas e trajetórias numa conjuntura que alia sistemas de disposições individuais a condições sociais de existência, num movimento que organiza o passado em relação ao presente. Alia-se aos pressupostos teóricos a pesquisa qualitativa baseada em bibliografias referentes, documentos históricos da Igreja Católica, jornais, revistas e entrevistas. Buscando, num processo de longa duração, a forma com que a instituição religiosa se apropriou da imagem como elemento simbólico para a "educação do espírito", a abordagem parte da utilização das artes sacras, passando por inventos ópticos como a câmara escura e a lanterna mágica, até chegar ao cinema. Este, inicialmente visto como um concorrente profano, logo passou a figurar como instrumento moral, moralizador e educador, cuja utilização demandou a implementação de organismos e documentos internacionais. No contexto do Brasil e da Bahia, esse estudo destaca como se deram as ações da hierarquia católica e do apostolado leigo, no engendramento 
de práticas institucionais e trajetórias de indivíduos e grupos no que concerne à formação para o cinema e pelo cinema.

Tal pesquisa tem continuidade no doutorado pelo Programa de Pós-Graduação em Memória: Linguagem e Sociedade da UESB, iniciado em 2012. O objetivo principal é compreender como se estruturou, entre os anos 1950 e 1970, uma rede de formação pelo e para o cinema no Brasil, sob iniciativa católica, que inclui ações desde a infância, como o Plano de Educação Cinematográfica para Crianças (Plan de Niños/Cineduc), até a idade adulta, como os cursos de aperfeiçoamento e de nível superior, considerando a triangulação entre essas práticas e as trajetórias individuais e sociais envolvidas num contexto-ambiente em que foram possíveis. O objeto é, portanto, compreendido sob o vértice da relação ação-agente-estrutura, sob a escolha teórico-metodológica pela sociologia dos processos e configurações de Norbert Elias e pela filosofia da ação ou disposicional de Pierre Bourdieu, a partir das possibilidades que seus modelos conceituais oferecem de tomarmos as redes relacionais humanas no fluxo do tempo e a concatenação entre eu e nós, ação e estrutura, passado e presente, corpo e personalidade, apreensão e transmissão de conhecimentos.

Outra pesquisa que toma a relação entre memória, cinema e processos de formação é a de Veruska Anacirema Santos da Silva, aluna da primeira turma do mestrado em Memória: Linguagem e Sociedade, que defendeu, em 2010, a dissertação intitulada Memória e Cultura: cinema e aprendizado de cineclubistas baianos dos anos 1950. Pensando o cinema como uma matriz societária de elaboração de saberes, fazeres e significados para a vida, propõe uma reflexão sobre as possibilidades de significação social entretidas nas práticas do cinema e na legitimação dessa expressão lúdico-artística como experiência capaz de inscrever-se na memória de indivíduos e grupos, participando da estruturação de formas de ver, entender e se posicionar no mundo. Faz isso observando as trajetórias de sete indivíduos (Hamilton Correia, Guido Araújo, Rex Schindler, Roque Araújo, Glauber Rocha, Geraldo Sarno e Orlando Senna) que dedicaram a vida à sétima arte, refletindo sobre os aprendizados proporcionados pelo cinema obtidos por tais agentes e seus efeitos nos seus percursos de 
vida. Toma as práticas de cinema para tratar do seu potencial enquanto modalidade específica de formação cultural, e desde aí, com lugar nas maneiras de construção dos fundos de conhecimento produzidos e reproduzidos socialmente.

Em 2012, Glauber Brito Matos Lacerda defendeu, também no mestrado em Memória: Linguagem e Sociedade, a dissertação intitulada Der Leone have sept cabeças: imagens da memória no cinema de Glauber Rocha. O trabalho de pesquisa se propôs a investigar como a trajetória social de Glauber Rocha (1939-1981) lhe ofereceu um acervo simbólico que, dada uma configuração social específica, possibilitou a expressão artística do cineasta no filme Der Leone havesept cabeças, realizado em 1970. Faz isso observando as interconexões estabelecidas pelas redes sociais em que o artista esteve inserido, delimitando a pesquisa na formação do cineasta nos campos cinematográfico, no qual política e estética não se distinguem, e religioso. Lança mão da Teoria Simbólica, de Norbert Elias, para entender a transmissão geracional de conhecimento, e toma a categoria de habitus, utilizada por Pierre Bourdieu, visando a compreender a incorporação de conhecimento pelo agente, sendo este capaz de ser expresso, dadas as condições sociais em que os indivíduos se encontram.

Outra pesquisa de mestrado pelo PPGMLS resultou na dissertação realizada por Mirela Souto Alves, defendida em 2012, intitulada A Grande Feira: cidade, cinema e memória na obra de Roberto Pires. O trabalho teve por objetivo entender, a partir da trajetória do cineasta baiano Roberto Pires, de que forma a cidade de Salvador comparece no seu filme A Grande Feira (1961) e, nesse aspecto, avaliar como a formação dele teve influência em sua expressão fílmica, considerando especialmente nesse filme a sua perspectiva de enquadramento da cidade na qual vivia, bem como, talvez, a sua pretensão de eternizá-la na memória. Para dar conta desse estudo, lançou mão dos aportes teóricos de Norbert Elias, a partir da relação de interdependência que estabelece entre os indivíduos e a sociedade, além da noção de transmissão e incorporação de conhecimento. Nesse sentido, a memória é entendida como um saber socialmente incorporado. Também utilizou autores como Antônio 
Risério e Maria do Socorro Carvalho, especificamente seus estudos sobre a cidade de Salvador e o seu processo de modernização, para entender o contexto em que Roberto Pires vivia e sua relação com aquele espaço urbano. Assim, acredita que a articulação temática entre cinema, cidade e memória é relevante e se explicita de forma significativa em A Grande Feira.

Em 2014, outra dissertação defendida no PPGMLS, foi a da aluna Cristina Leilane Azevedo Fernandes, intitulada Cinefilia em Vitória da Conquista: memórias de uma prática cinematográfica, que toma a interdependência entre cinema, memória e processos de formação cultural para analisar as práticas de cinefilia em Vitória da Conquista. A pesquisa mapeou trajetórias de cinéfilos na cidade, bem como realizou um levantamento das práticas de cinema aliadas aos percursos de formação, objetivando compreender os mecanismos de transmissão dos aprendizados nas ações de produção e consumo cinematográfico.

Memória social e políticas culturais nas ações de cinema do SESC é o título da dissertação de mestrado defendida em 2015 por
Marcelo Costa Lopes, também no PPGMLS. O estudo teve por objetivo compreender a política de cinema do Serviço Social do Comércio (SESC) no Brasil, suas referências e estruturação para consecução de um amplo programa de formação de público para o cinema não comercial no país. Ancorando-se na contribuição teóricometodológica do sociólogo Norbert Elias, tomou-se a política como síntese de um processo social complexo, disposta na dinâmica das configurações formadas por indivíduos mutuamente orientados e que, nos termos propostos pelo estudo, implicaram no emaranhado de fatores referentes ao contexto social que se delineou entre os anos 1940 e os dias atuais. Demonstra como as práticas socialmente constituídas com a mediação da estrutura do Serviço Social do Comércio contribuem para percursos de aprendizagem que mobilizam estoques de conhecimento mediados simbolicamente, veiculando padrões de comportamento para viabilizar consumo cinematográfico distinto.

Algumas pesquisas, embora não tomem diretamente a abordagem da formação cultural e não aportem suas discussões em pressupostos teórico-metodológicos da Sociologia, como os citados 
anteriormente, optando preferencialmente por campos do conhecimento como a História e a Filosofia, consideram como fundamental a relação entre cinema e memória.

Entre esses trabalhos, está a dissertação de Sara Mantin Rodrigues, defendida no mestrado do PPGMLS, em 2011, sob o título Imagem cinematográfica e memória no diálogo entre Bergson e Deleuze. A pesquisa investiga de que modo a concepção de memória, traçada a partir da perspectiva teórica inaugurada pelo filósofo Henri Bergson no livro Matéria e Memória colabora para fundamentar as concepções dos dois regimes de imagem desenvolvidos por Gilles Deleuze em Cinema 1 - A Imagem-movimento e Cinema $2-A$ Imagem-tempo. As imagens produzidas em dois momentos do cinema (o clássico e o moderno) se contrapõem na medida em que estabelecem uma relação diferenciada com o tempo e com o espaço, ou, em termos bergsonianos, com o espírito e com a matéria. Se a imagem-movimento se estrutura de maneira esquemática baseada numa lógica sensóriomotora, isto é, se ela se desenvolve a partir de um tempo impregnado de espaço, a imagem-tempo chega com uma novidade: o tempo puro, que nada mais é senão aquilo que Bergson chamou duração. Do mesmo modo que se valeu do conceito de duração para constituir parte de sua teoria, Deleuze voltará a beber muitas vezes na fonte bergsoniana para concluir seu pensamento. Interessada em observar, particularmente, de que forma a memória participa desse processo, trabalhou num campo de discussão fundamentalmente teórico, interpretando alguns aspectos da teoria mnemônica de Bergson e cinematográfica de Deleuze no que tange, especialmente, à profunda dependência da articulação conceitual da segunda (acerca das duas noções de imagem) em relação à primeira (acerca do que se entende por memória).

Também interessado na relação entre cinema e memória, sob as noções interpretativas da Filosofia, Rogério Luiz Silva de Oliveira, egresso do mestrado do PPGMLS e ingresso no doutorado pelo mesmo programa em 2013, propõe uma pesquisa em torno do pressuposto de que a memória age no processo de criação do diretor de fotografia de trabalhos audiovisuais. A participação do fotógrafo na construção fílmica é analisada do ponto de vista filosófico, elaborado em conformidade com as ideias dos filósofos Henri Bergson e Gilles 
Deleuze acerca do conceito de memória. O modelo analítico-filosófico adotado vem, principalmente, da inspiração dos trabalhos As duas fontes da moral e da religião e Proust e os Signos (respectivamente). Do primeiro, extrai a ideia de função fabuladora, um tipo de imaginação, logo alicerçado na memória; no segundo, em que Deleuze propõe a sua filosofia por dentro da obra Em busca do tempo perdido, de Marcel Proust, a iniciativa deleuzeana de retomar algumas teses proustianas influencia-o de tal modo que busca na própria construção literária de Proust os argumentos necessários ao entendimento e argumentação sobre a memória que os interessa. Lançando mão dessa metodologia, propõe uma imersão nas obras fotográficas de Edgar Brasil, Dib Lutfi e Walter Carvalho, três fotógrafos brasileiros que atuam/atuaram em diferentes momentos da cinematografia nacional e fazendo uso de distintas ferramentas estéticas de construção fotográfica.

Outra pesquisa a ser mencionada é a de Joslan Santos Sampaio, que, como aluno concluinte do PPGMLS em 2014, defendeu a dissertação Nem verdade, nem mentira: a ficção histórica $e$ cinematográfica. Na leitura adotada por ele, a "verdade", enquanto constructo discursivo, expressa a continuidade da afirmação última de que ela não passa de uma estratégia fictícia. A dissertação visa a discutir alguns aspectos das estratégias adotadas pela narrativa historiográfica e cinematográfica na produção estética da "verdade". Em outras palavras, tratou-se de operar com os dispositivos que regem a intersecção da História com o cinema. Revisitou-se uma fortuna crítica sob os imperativos históricos e cinematográficos da perspectiva da aporia da "verdade" até o deslocamento dessas narrativas para as noções de "prática" e "representação", ao passo em que se buscou rastrear pistas, por meio do método indiciário, a evidenciar um discurso que advoga pela busca de documentos/monumentos enquanto condição sine qua nom da construção da "verdade" enquanto "prova". Seguidamente, a leitura do filme A verdadeira história de Lena Baker, tido como "artefato" de ilustração para a análise, sublinhou, ainda, uma fabricação da memória enquanto fenômeno de entrelaçamento de uma sutil percepção do "real" e da sugestão provocada pela imaginação, o que exerce um controle sobre essas narrativas, a ponto de serem 
designadas de ficções controladas. A análise resultante desse estudo acusa que a "verdade" produzida pelas narrativas em tela é o resultado de valores e normas do seu tempo.

\section{As relações entre memória e cinema nos percursos teórico-metodológicos}

Como se pode observar a partir dos itinerários de pesquisa apresentados anteriormente, as abordagens relacionais entre memória e cinema tratadas nos trabalhos estão correlacionadas a campos distintos do conhecimento, como os da Sociologia, da Filosofia e da História, embora seja no âmbito da Sociologia da Cultura que se ancorem a maioria dos percursos descritos. A filiação aos dois grupos de pesquisa já mencionados justifica o maior interesse nas questões relacionadas aos processos formativos e à transmissão de aprendizados mediante produção e consumo cinematográfico.

Faz-se necessário, no entanto, destacar o papel fundamental na formação dos pesquisadores no âmbito da Sociologia da Cultura, trabalho criteriosamente desenvolvido pelo professor Edson Silva de
Farias, que organizou e promoveu atividades acadêmicas para viabilizar a ampliação da formação teórica daqueles vinculados ao CMD. Além disso, orientou as pesquisas para as dissertações de mestrado e teses de doutorado de boa parte dos integrantes do grupo. O enfoque dos estudos, planos de trabalho e pesquisas desenvolvidas pelo grupo se detiveram nas modalidades de compreensão social e na percepção sobre a repercussão desta na orientação das condutas. Essa perspectiva pautou a questão da memória e seus processos de ressignificação mediante dispositivos de aprendizagem e síntese simbólica, estes como lastro das possibilidades expressivas, interpretativas e da transmissão das experiências.

Compreendeu-se, assim, que a memória compõe a estruturação dos sistemas sociais, ou seja, viabiliza a manutenção de padrões interativos e institucionais, subjazendo também operações técnicas e científicas. Como processo de construção coletiva, compõe as condições de possibilidades do imaginário, o desenvolvimento das relações e o intercâmbio material dos sistemas sociais com a natureza. Ela fornece também os parâmetros para organização de sua dimensão 
1 Notas de aula nos Seminários Temáticos sobre Memória, Cultura e Desenvolvimento, em julho de 2005 , no Museu Pedagógico, durante o Curso de Especialização em Educação, Cultura e Memória, promovido pelo Departamento de Filosofia e Ciências Humanas da UESB espaço-temporal, sua configuração e seus ritmos de reprodução e mudança.

Essa discussão remeteu aos papéis que cumprem o conhecimento e a linguagem nas vivências e experiências humanas, o que significou, para muitos dos pesquisadores do grupo, a necessidade de inquirir aos processos sociais quais as condições de transmissividade dos saberes e fazeres, bem como as condições de sua incorporação. Para dar conta desse caminho teórico-metodológico que apontou a interdependência entre memória, saber incorporado (habitus), trajetórias e práticas (expressividades e sociabilidades) na construção de diversos objetos de pesquisa, foi necessário trazer a contribuição de sociólogos clássicos e contemporâneos, de fundamental importância para os estudos da cultura, entre os quais se destacaram Georg Simmel, Walter Benjamin, Norbert Elias e Pierre Bourdieu.

Além disso, a contribuição reflexiva de Farias em seus estudos sobre a questão da memória foi fundamental. Em sua síntese, argumenta que as nossas convicções se inscrevem no terreno da memória, e esta não pode existir sem o corpo humano e outros suportes materiais, porém não se reduz a eles. Ela se constitui na interface entre o dito e o não dito e porta quatro aspectos fundamentais: a linguagem, a experiência, o estoque de saber simbolicamente sintetizado e os discursos públicos. Para o autor ${ }^{1}$, que toma Norbert Elias (2002) em sua elaboração sobre a teoria simbólica como referência, a linguagem é o ponto de continuidade entre a capacidade natural humana de expressão e o modo histórico e social de realização da evolução humana, traduzindo-se e concretizando-se das mais diversas formas. A experiência é, antes de qualquer coisa, o ato consentido, e este se refere ao estoque de conhecimento simbolicamente sintetizado. $\mathrm{O}$ ato humano apenas estará dotado de sentido, tornar-se-á um gesto, à medida que for engendrado pelo estoque de conhecimento de que a humanidade tem se dotado. Esse engendrar do ato pela experiência simbolicamente sintetizada apenas se possibilita pelos canais de transmissão, ou seja, pelas mais diversas manifestações do discurso.

Assim, pode-se dizer que o que se realiza são processos permanentes de aprendizados. 
Processos que parametram as possibilidades expressivas e participam efetivamente para formulação dos estilos de vida, que, por sua vez, estão na contrapartida das imagens de mundo, cosmologias, estas compreendidas como arquiteturas nas quais as grades de classificação estão vinculadas às narrativas, à maneira da forma de encadeamentos dos episódios da vida, que, em certa medida, determinam e situam as possibilidades de expressão. Nesse sentido, a memória é sempre uma construção, quer falemos de percepção e sentimentos, quer mencionemos a memória organizada linguisticamente ou por intermédio de imagens e mecanismos de lembrança, o que, a rigor, constituem os fundos de conhecimento em processo, acumulados e mobilizados mediante ações dos grupos humanos.

Então, quando se trata da relação entre memória, cinema e processos de formação cultural, são essas referências teórico-analíticas que informam a maioria dos itinerários das pesquisas, e embora alguns percursos tenham feito opção pela discussão filosófica da memória para tratar do cinema, quando o assunto refere-se aos aprendizados que potencializam a sua configuração, seja em âmbito geral ou específico, não se deixa de considerar que certas expressões do indivíduo só são possíveis porque trazem, em sua potência, referências de continuidade, de ruptura ou de ressigificação daquilo que se deu a partir das experiências de outras pessoas, ou seja, dos processos de transmissão do conhecimento entre membros da mesma geração ou de gerações distintas. Melhor dizendo, compreende-se que os percursos de formação são reveladores da importância das condições de transmissividade e de incorporação dos saberes entre indivíduos para continuidade ou mudanças nas trajetórias e práticas cinematográficas.

Nessa dimensão, outra importante referência que comparece nas argumentações que informam os percursos das pesquisas trata-se da noção de habitus, que Pierre Bourdieu recupera da escolástica medieval e retrabalha, tomando-o em sua acepção de princípio gerador de práticas distintas e distintivas, de classificação, visão e divisão e gostos (BOURDIEU, 1996, p. 22). Ao reapresentar o conceito de habitus, Bourdieu (2001, p. 169) afirma que uma das principais funções da noção de habitus consiste em superar dois erros complementares cujo princípio é a visão escolástica: 
De um lado, o mecanismo segundo o qual a ação constitui o efeito mecânico da coerção de causas externas, de outro o finalismo, segundo o qual, sobretudo por conta da ação racional, o agente atua de maneira livre, sendo a ação o produto de um cálculo das chances e dos ganhos. Contra ambas as teorias, convém ressaltar que os agentes sociais são dotados de habitus, inscritos nos corpos pelas experiências passadas: tais sistemas de esquemas de percepção, apropriação e ação permitem tanto operar atos de conhecimento prático, fundados no mapeamento e no reconhecimento de estímulos condicionais e convencionais a que os agentes estão dispostos a reagir, como também engendrar, sem posição explícita de finalidades nem cálculo racional de meios, estratégias adaptadas e incessantemente renovadas, situadas porém nos limites das constrições estruturais de que são produto e que as definem.

Como se pode observar, Bourdieu faz questão de ressaltar a inscrição do habitus nos corpos. Para o sociólogo francês, o habitus, portanto, é um produto da história que produz práticas individuais e coletivas, e estas, por sua vez, estabelecem os limites de liberdade dos indivíduos pela opção entre diferentes estratégias de ação, que dizem respeito aos espaços de possibilidades dos mundos sociais. Embora não seja possível aprofundar aqui a noção de habitus e a sua vinculação, na teoria praxiológica, à noção de campo, esta constitui uma das bases nas quais se assentam as reflexões que amparam as pesquisas do referido grupo de pesquisa.

Essas reflexões estão ancoradas na compreensão acerca da teia de ações humanas que desenvolveu o cinema, que foi, ao longo do processo histórico, estruturando ambiências de sociabilidade, aprendizados e instituições e delineando as profissões do âmbito cinematográfico em diversos lugares do mundo. Também comparece a percepção de que os fluxos e relações entre os indivíduos possibilitaram combinar desenvolvimentos tecnológicos, instituições e criatividade às necessidades humanas relacionadas à arte e ao entretenimento e, ao mesmo tempo, gerar tensões entre modos distintos de significação, que, via de regra, opõem indústria e arte no campo cinematográfico.

São muitos os exemplos de trajetórias e práticas sociais relacionadas ao consumo cinematográfico, reveladores de processos de aprendizado que parametram possibilidades que se expressam na 
tessitura das sociabilidades constituídas ao longo do tempo sob os estatutos da produção e do consumo. Nessas dinâmicas, além da intensificação das relações sociais e econômicas que foram constituindo a potente indústria cinematográfica, também foram surgindo agentes envolvidos na produção dos filmes, críticos, jornalistas especializados, revistas especializadas, cineclubes, encontros e seminários, mostras e festivais, cursos livres e departamentos nas universidades, escolas e institutos de cinema.

Enfim, surgiram, a partir das possibilidades de compartilhamento propiciadas pela produção e consumo de filmes, diversas atividades que tomaram o cinema como uma questão a ser tratada, tanto na dimensão mais restrita quando o gosto individual pelo cinema se torna uma filia, a exemplo das práticas de colecionismo, quanto na dimensão mais ampla, social, quando se estruturam organizações e grupos, portadores e defensores dos mais diversos interesses, incluindo os mercadológicos.

A filiação da maioria dos percursos de investigação do grupo de pesquisa à teoria configuracional desenvolvida por Norbert Elias possibilitou a compreensão de que produção e consumo cinematográfico no mundo contemporâneo estão perpassados por articulações e tensões que remetem ao engate entre memória, cultura e desenvolvimento, ou seja, relações que dizem respeito à interconexão entre processos sociais que possibilitaram tanto o desenvolvimento tecnológico e comunicacional quanto resultaram na globalização e na preponderância das relações de mercado. Não há mais dúvidas de que, no âmbito da cultura, os mercados de produção e consumo de bens culturais constituem parte significativa das atividades econômicas que geram riquezas e criam empregos diretos e indiretos por todo o planeta. Entretanto, na contrapartida desse movimento, não há como desconsiderar que a ampliação da produção e o ganho econômico crescente não têm se refletido diretamente em mudanças significativas na melhoria da formação cultural e educacional e das condições de consumo de grande parte das populações mundiais.

Nessa complexa configuração, observa-se, na contrapartida desse processo - articulado tensamente entre corporações transnacionais e governos nacionais -, que se estruturam mundialmente 
redes compostas por instituições e organizações não governamentais preocupadas em viabilizar expressões e consumos audiovisuais em outros circuitos de divulgação, possibilitando acesso às produções que não alcançam o hegemônico circuito comercial. Destaca-se aqui a ampliação do número de clubes de cinema, cinematecas, festivais e mostras (competitivas ou não), que viabilizam, no Brasil e no mundo, a exibição das mais diversas produções cinematográficas e o intercâmbio entre cineastas, produtores, intelectuais e artistas.

Esse âmbito da configuração cinematográfica, considerado marginal ou alternativo por alguns estudiosos, é tributário da ação dos cineclubes que historicamente comparecem como organizações fundamentais para a formação de núcleos de discussão intelectual sobre cinema em diversos lugares do mundo. Segundo Lisboa (2007, p. 359), as atividades promovidas pelos cineclubistas na América Latina (especialmente no Brasil, Argentina e Cuba), respeitando as especificidades de cada país, foram responsáveis pela abertura de um intenso debate intelectual internacional sobre os impasses da implantação de uma indústria cinematográfica com preocupações socioculturais em países com mercados onde a hegemonia da produção norte-americana já era preponderante. Esses debates foram marcados pela discussão da renovação temática para a produção de cinema nacional, destacando o cinema como produto cultural. Nas diversas revistas e boletins informativos dos cineclubes, observam-se discussões teóricas nas quais o cinema comparece como importante meio para difusão cultural e formação de públicos com elevada capacidade crítica.

Não por acaso, trajetórias cineclubistas comparecem em vários dos trabalhos realizados pelos pesquisadores do grupo de pesquisa, seja mediante os processos de formação dos cineastas, como foi o caso de Glauber Rocha, Geraldo Sarno e Orlando Senna, na Bahia, ou numa perspectiva mais ampla, mediante trabalho realizado por cineclubistas e críticos como Paulo Emílio Salles Gomes, em São Paulo, Walter da Silveira, em Salvador, Jacques do Prado Brandão e Ciro Cerqueira, em Belo Horizonte, Plínio Sussekind Rocha e Alípio Barros, no Rio de Janeiro, e Paulo Fontoura Gastal, em Porto Alegre, entre os anos 40 e 60 do século passado, o que criou condições para a realização de encontros entre cinéfilos das diversas regiões do país, que compartilhavam a 
percepção do cinema como manifestação cultural, ao tempo em que consideravam ser o consumo cinematográfico um meio para viabilizar a manutenção ou a transformação de atitudes humanas e de condutas cotidianas.

Vale lembrar que, no Brasil, esse movimento, marcado pela renovação do teatro, pelo surgimento de importantes inovações na música popular e pelo aparecimento do Cinema Novo, explicitou, em diversas ambiências da produção artística, a presença de representantes de gerações influenciadas por experiências de formação cultural marcada pela frequência aos clubes de cinema. E essas ambiências também foram responsáveis pelo surgimento das mostras e festivais de cinema que começam a aparecer em vários lugares do país.

A expressão dos aprendizados a partir dessas experiências reveladas pelas empirias das pesquisas realizadas traduz-se na composição de várias práticas pedagógicas.Voltando aos escopos das pesquisas até agora realizadas pelo grupo, pode-se perceber que, nessa dimensão compreensiva da relação entre cinema e memória, está ressaltada, na construção dos objetos, a potência formativa do cinema. A apropriação desse elemento mediador e o sentido atribuído a ele por indivíduos e grupos associam-se a distintas possibilidades de composição de acervos de conhecimentos relacionados, num contínuo fluxo de mão dupla, a competências, maneiras, gostos, constitutivos do indivíduo e das suas formas de ver, refletir, fazer e interagir no mundo.

\section{Referências}

ALVES, Mirela Souto. A Grande Feira: cinema, cidade e memória na obra de Roberto Pires. Dissertação (Mestrado em Memória: Linguagem e Sociedade) - Universidade Estadual do Sudoeste da Bahia, Vitória da Conquista, 2012

BOURDIEU, Pierre. Meditações Pascalianas. Rio de Janeiro: Bertrand Brasil, 2001

\section{Razões Práticas. São Paulo: Papirus, 1996.}

DUARTE, Rosália Maria. Filmes, Amigos e Bares: a formação de cineastas na cidade do Rio de Janeiro. Tese (Doutorado em Educação) - Pontifícia Universidade Católica do Rio de Janeiro, Rio de Janeiro, 2000.

ELIAS, Norbert. Teoria Simbólica. Oeiras: Celta, 2002. 
FERNANDES, Cristina Leilane Azevedo. Cinefilia em Vitória da Conquista: memórias de uma prática cinematográfica. Dissertação (Mestrado em Memória: Linguagem e Sociedade) - Universidade Estadual do Sudoeste da Bahia, Vitória da Conquista, 2014.

GUSMÃO, Milene: Uma Janela para o Mundo: memória e cinema em Vitória da Conquista._Dissertação (Mestrado em Memória Social e Documento) - Universidade Federal do Estado do Rio de Janeiro, Rio de Janeiro, 2001

Dinâmicas do Cinema no Brasil e na Bahia: trajetórias e práticas do século XX ao XXI. Tese (Doutorado em Ciências Sociais) Universidade Federal da Bahia, Salvador, 2008

LACERDA, Glauber Brito Matos. Der Leone Have Sept Cabeças: imagens da memória no cinema de Glauber Rocha. Dissertação (Mestrado em Memória: Linguagem e Sociedade) - Universidade Estadual do Sudoeste da Bahia, Vitória da Conquista, 2012.

LOPES. Marcelo Costa. Memória Social e Políticas Culturais nas Ações de Cinema do SESC. Dissertação (Mestrado em Memória: Linguagem e Sociedade) - Universidade Estadual do Sudoeste da Bahia, Vitória da Conquista, 2015.

LISBOA, Fátima S. G. "O cineclubismo na América Latina: idéias sobre o projeto civilizador do movimento francês no Brasil e na
Argentina (1940-1970)". In: CAPELATO, Maria; MORETIN, Eduardo; NAPOLITANO, Marcos e SALIBA, Elias Thomé. História e Cinema: dimensões históricas do audiovisual. São Paulo: Alameda Casa Editorial, 2007.

OLIVEIRA, Rogério Luiz Silva de. Pensar com a Luz: a memória criativa do diretor de fotografia. Qualificação (Doutorado em Memória: Linguagem e Sociedade) - Universidade Estadual do Sudoeste da Bahia, Vitória da Conquista, 2014

RODRIGUES, Sara Martin. Imagem Cinematográfica e Memória no Diálogo entre Bergson e Deleuze. Dissertação (Mestrado em Memória: Linguagem e Sociedade) - Universidade Estadual do Sudoeste da Bahia, Vitória da Conquista, 2011.

SAMPAIO, Joslan Santos. Nem Verdade, nem Mentira: a ficção histórica e cinematográfica. Dissertação (Mestrado em Memória: Linguagem e Sociedade) - Universidade Estadual do Sudoeste da Bahia, Vitória da Conquista, 2014.

SANTOS, Raquel Costa. Lição de Coisas: Igreja Católica e formação cultural para o cinema no Brasil e na Bahia. Dissertação (Mestrado em Ciências Sociais) - Pontifícia Universidade Católica de São Paulo, São Paulo, 2009.

O Projeto Católico Latino-Americano de Educação pelo/para o Cinema na Infância: o Plan de Niños e a experiência brasileira. 
Qualificação (Doutorado em Memória: Linguagem e Sociedade) Universidade Estadual do Sudoeste da Bahia, Vitória da Conquista, 2014.

SILVA, Veruska Anacirema Santos da. Memória e Cultura: cinema e aprendizado de cineclubistas baianos dos anos 1950. Dissertação (Mestrado em Memória: Linguagem e Sociedade) - Universidade Estadual do Sudoeste da Bahia, Vitória da Conquista, 2010. 